\title{
APRESENTAÇÃO DA FICHA DE INVENTÁRIO E HISTÓRIA DO MUSEU ESCOLAR DO COLÉGIO MARISTA ARQUIDIOCESANO DE SÃO PAULO
}

\author{
Katya Zuquim Braghini \\ Pontifícia Universidade Católica de São Paulo \\ katya.braghini@yahoo.com.br \\ Paula Maria de Assis \\ Pontifícia Universidade Católica de São Paulo \\ pmassissp@hotmail.com \\ Ricardo Tomasiello Pedro \\ Pontifícia Universidade Católica de São Paulo \\ rpedro@colegiosmaristas.com.br \\ Raquel Quirino Piñas \\ Pontifícia Universidade Católica de São Paulo \\ memorialarqui@colegiosmaristas.com.br
}

\begin{abstract}
RESUMO
O objetivo do artigo é apresentar um breve histórico do patrimônio escolar, científico do Museu Escolar do Colégio Marista Arquidiocesano de São Paulo; registrar o atual estado das peças; expor os primeiros trabalhos com o inventário, pensando-o como ferramenta de gestão e peça chave para a produção de novos conhecimentos, dando destaque à construção do instrumento de identificação de peças ou ficha de inventário. Levando em conta que a montagem de tal ficha deve seguir critérios específicos que tem relação com a definição da coleção, diferentes modos de identificação e classificação. Levou-se em consideração às indicações dadas pelo Museu de Astronomia e Ciências afins (MAST) para a catalogação de objetos científicos associados a interesses de investigação particulares à história da educação.
\end{abstract}

Palavras-chave: Museu escolar. Patrimônio educativo. Inventário.

\section{PRESENTATION OF THE INVENTORY RECORD AND HISTORY FORM OF THE SCHOOL MUSEUM OF THE MARISTA ARCHDIOCESAN COLLEGE OF SAO PAULO}

The aim of this article is to present a brief history of both scientific and school property of the School Museum of the Marista Archdiocesan College of Sao Paulo; to register the current state of the objects; to expose the initial works through inventory, thinking of it as a management tool and key piece for the production of new knowledge, thus emphasizing the elaboration of this intrument of identification of museum objects, or inventory form. There is intention to record the steps that defined the inventory form, taking into account that the elaboration of such a form must follow specific criteria that relate to the definition of collection, different modes of identification and classification. The indications given by the Museum of Astronomy and Related Sciences (MAST) were taken into account for the cataloging of scientific objects associated with specific research interests with regards to the history of education.

Keywords: School museum. Educational heritage. Inventory. 


\section{PRESENTACIÓN DE LA FICHA DE INVENTARIO E HISTORIAL DEL MUSEO ESCOLAR DEL COLEGIO MARISTA ARCHIDIOCESANO DE SÃO PAULO}

El objetivo del artículo es presentar un breve historial del patrimonio escolar, científico del Museo Escolar del Colegio Marista Archidiocesano de São Paulo; registrar el actual estado de las piezas; exponer los primeros trabajos con el inventario pensándolo como herramienta de gestión y pieza clave para la producción de nuevos conocimientos, dando realce a la construcción de identificación de piezas o ficha de inventario. Llevando en cuenta que el montaje de tal ficha debe seguir criterios específicos que tienen relación con la definición de la colección, diferentes modos de identificación y clasificación. Se llevó en consideración las indicaciones dadas por el Museo de Astronomía y Ciencias afín (MAST) para la catalogación de objetos científicos asociados a intereses de investigación particulares a la historia de la educación.

Palabras clave: Museo escolar. Patrimonio educativo. Inventario.

\section{INTRODUÇÃO}

O Museu Escolar do Colégio Marista Arquidiocesano de São Paulo é patrimônio científico e escolar de uma instituição católica, confessional, fundada em 1858. Guarda uma coleção iniciada há 157 anos, composta por diversos objetos vinculados ao ensino das ciências (Física, Química, História Natural), levando em conta suas subdivisões disciplinares. Parte dos instrumentos são materiais escolares, concebidos para o uso didático; outros são instrumentos de precisão que foram adaptados para a ação escolarizada. ${ }^{1}$

Atualmente, o colégio, por meio de seu Memorial, órgão criado no ano de 2008 para a salvaguarda do patrimônio escolar, é responsável pela observação do estado de conservação de peças ainda em uso; análise diagnóstica das coleções museológicas; guarda e conservação de documentos diversos.

O artigo apresenta um breve histórico desse patrimônio para, na sequência, registrarmos os primeiros trabalhos com o inventário, aqui pensado como ferramenta de gestão e peça chave para a produção de novos conhecimentos, sejam eles acadêmicos ou não. Apresentamos o modelo da ficha de inventário que está sendo utilizada para o tratamento das informações que serão inseridas num banco de dados gerado junto ao sistema Pergamum integrado de bibliotecas, mas, neste caso, pensado para a base de dados museológica

\footnotetext{
${ }^{1}$ Todos os trabalhos com a coleção fazem parte do projeto "Museu Escolar do Colégio Marista Arquidiocesano de São Paulo (fase 1): planejamento e organização do inventário dos instrumentos científicos” desenvolvido na Pontifícia Universidade Católica de São Paulo, em parceria com o Colégio Marista Arquidiocesano de São Paulo. Este projeto é financiado pelo CNPq.
} 
denominada Pergamum Museu. ${ }^{2}$ A apresentação da ficha em base de dados informatizada e as devidas explicações sobre a sua construção, a escolha dos itens de registro e o seu funcionamento são os elementos centrais no presente texto. ${ }^{3}$

\section{BREVE HISTÓRICO DA COLEÇÃO DE OBJETOS CIENTÍFICOS DO COLÉGIO MARISTA ARQUIDIOCESANO}

Em 1856, no bairro da Luz, região central da cidade de São Paulo, sob determinação do bispo D. Antônio Joaquim de Melo (1852 - 1861), foi solicitada aos freis capuchinhos de Sabóia a implantação do Seminário Episcopal de São Paulo no bairro da Luz. Por conta da sua localização privilegiada e para atender a demanda crescente, em 1858, ao lado do Seminário, foi instalado o Colégio Diocesano, destinado a receber os alunos não aspirantes ao sacerdócio.

Por mais duas décadas (de 1858 a 1879), foi a Ordem Capuchinha responsável pelo colégio. Em 1904, por ordem do bispo de São Paulo, D. José de Camargo separou-se o Seminário do Colégio tendo os padres Diocesanos como mantenedores. O Colégio conseguiu a sua primeira equiparação ao Colégio Pedro II em (1900) fato que impulsionou o aumento das matrículas, chegando a ter quase 200 alunos matriculados.

Em 1908, foi concedida a guarda da instituição aos Irmãos Maristas. A Diocese de São Paulo foi elevada a Arquidiocese e, portanto, a escola passou a se chamar Colégio Arquidiocesano de São Paulo e oferecia os cursos primário e secundário, em regime de internato ou semi-internato. ${ }^{4}$

Quando assumiram o Colégio, os Irmãos Maristas herdaram o Gabinete de Ciências que fora montado pelo Frei Germano d'Annecy, até então o responsável por ministrar as aulas de Física, Matemática, Astronomia, Botânica e Mineralogia em seu conhecido gabinete dentro da escola. Após a saída dos Capuchinhos, o Padre João Batista Vanesse, designado o diretor da instituição, listou, em 1900 os instrumentos e objetos científicos no documento de equiparação do colégio ao Ginásio Nacional. Conforme o documento, “o Museu Escolar,

\footnotetext{
${ }^{2}$ O Pergamum - Sistema Integrado de Bibliotecas é um sistema informatizado de gerenciamento de dados, direcionado aos diversos tipos de Centros de Informação.

${ }^{3}$ Este texto foi originalmente apresentado no IV Simpósio Iberoamericano: História, Educação, Patrimônio Educativo realizado no Centro Paula Souza entre os dias 02 a 04 setembro de 2015.

${ }^{4} \mathrm{O}$ regime de internato vigorou durante 110 anos, da fundação do colégio, em 1858, até o ano de 1968. Até o ano de 1969, a instituição dedicou-se exclusivamente à instrução de estudantes do sexo masculino, começando a admitir alunas no ano seguinte, 1970. Durante décadas recebeu principalmente crianças e jovens de famílias economicamente privilegiadas, residentes no interior paulista e outros estados. Os antigos alunos matriculavamse em cursos concorridos como Medicina, Direito e Engenharia, e seguiam carreiras de prestígio na política, administração pública e grandes companhias.
} 
gabinete de Física e laboratório de Química se apresentavam como ambientes diferenciados organizados em um mesmo espaço". ${ }^{5}$ Guardava uma "bela coleção de mármores"; "grande coleção de pedras"; "importante coleção de conchas"; "coleção regular de aves, quadrúpedes, anfíbios, peixes e cobras embalsamadas e em vidros de álcool”; "riquíssima coleção de moedas antigas" e "completa coleção de moedas novas".

O gabinete de Física e Química possuía 61 instrumentos, acompanhando ao que era estabelecido como currículo obrigatório, apresentado no colégio secundário modelar. Contava com vidrarias diversas, elementos químicos, bombas pneumáticas, bomba de vácuo, máquina de Winchester, máquina de Wimshurst, fonte de Heron, quadros parietais e o modelo anatômico humano da Maison Deyrolle (BRAGHINI; PIÑAS; PEDRO, 2014). Gabinete de Física e Museu Escolar, voltados ao estudo da História Natural, coexistiram em um mesmo espaço.

No final dos anos 1920, os Maristas constroem uma nova sede, no bairro da Vila Mariana. O novo edifício foi pensado para atender, receber e ampliar o museu pedagógico e os laboratórios com o intuito de se tornar "um dos melhores estabelecimentos congêneres", segundo a indicação do inspetor federal de ensino, no Livro de ocorrências, em 1935 (BRAGHINI; PEDRO; PIÑAS, 2014, p. 39).

O Museu Escolar, ao longo de sua existência, primeiro como espaço didático, planejado e organizado para as aulas, depois como ambiente de salvaguarda de artefatos, não deixou de receber acréscimos ao longo de sua história. Fosse por compra de novos objetos ou por doação feita por professores e ex-alunos, hoje a coleção abriga peças de diversos períodos do século XX. Por serem, ao mesmo tempo, materiais escolares e tecnocientíficos, correram riscos de descarte sem critérios quando deixam de serem "inovações".

Por uma contagem ainda imprecisa, existem 800 peças, usadas somente para o ensino de Física e Química, adquiridas entre a segunda metade do século XIX e o início dos anos 1980. Há instrumentos para o ensino de Mecânica, Astronomia, Hidrostática, Pneumática, Calorimetria, Ótica, Eletricidade, Magnetismo, Acústica, grande parte, adquirida antes dos anos 1930.

Observando as peças que estão em exposição, percebe-se o registro de diversos fabricantes de casas estrangeiras: Maison Deyrolle, Les Fils d'Emilie Deyrolle, Ducretet, Machlet, Rodriguet \& Massiot, Max Kohl, Winkel Zeiss, Carl Zeiss, Welch Scientific Company, Hartmann and Brown, WM Welch Scientific Company, entre outros. Há também

\footnotetext{
${ }^{5} \mathrm{O}$ documento da primeira equiparação do Colégio Arquidiocesano de São Paulo está depositado no Arquivo
} 
empresas brasileiras, tais como: Otto Bender, Franz Sturn Cia Ltda, Techné São Paulo, Meister Irmãos etc. A coleção para o ensino de História Natural contém modelos anatômicos, animais taxidermizados, coleções de mineralogia, exemplares arqueológicos etc.

A coleção do colégio passou por uma fase de abandono, entre o final dos anos 1950 e meados dos 1960 e, especialmente, os instrumentos para ensino de Física e Química sofreram o desgaste natural do tempo, agravados com o acondicionamento inadequado. Por meio dos relatos de professores, hoje aposentados, descobriu-se que o espaço de guarda dos instrumentos constituiu-se em um depósito caótico de coisas: lentes perdidas, lâmpadas quebradas, peças soltas, vidros rachados, peças de bronze oxidadas, cobertas com zinabre, infestadas por cupins, correias de couro partidas etc. ${ }^{6}$

Até o ano de 2008, muitas das informações relativas aos instrumentos para o ensino de Física - uma das coleções que compõe o Museu Escolar - havia se perdido. As peças também estavam aglomeradas nos armários, sem identificação e mantidas fechadas, apenas recebendo cuidados de higienização.

No caso do Colégio Arquidiocesano, houve um impulso nas ações de preservação dos acervos históricos institucionais com as comemorações de centenário e sesquicentenário em 2008. A partir dos trabalhos de recuperação das informações sobre esse acervo, foram montadas ações de valorização de seu patrimônio e divulgação de sua existência junto à comunidade escolar.

Atualmente, os objetos científicos estão dispostos em armários distribuídos nos átrios (do $1^{\circ}, 2^{\circ}$ e $3^{\circ}$ andares) e pelos corredores do $3^{\circ}$ andar do edifício. Foram adquiridos 47 novos armários para a guarda dos objetos que continuam expostos nos corredores e átrios destes três pisos do edifício escolar. Os armários destinados aos aparelhos para o ensino de Física foram revestidos de insulfilm, padrão museu, com o intuito de minimizar os efeitos da fotodegradação, fato que ainda não aconteceu com o mobiliário destinado aos animais taxidermizados.

No laboratório de Biologia, são mantidos, em armários dispostos na sala e em um mezanino, os antigos modelos de Botânica, Zoologia e Fisiologia usados nas aulas de História Natural, bem como a coleção de rochas para as aulas de Mineralogia. É possível constatar pelo estado de conservação que a coleção de História Natural está em melhores condições,

Nacional, na cidade do Rio de Janeiro. Arquivo Nacional - Série Educação IE4 - 134, 3791/311.

${ }^{6}$ A solução para tais problemas teria sido o descarte de peças ou a guarda de partes da coleção e houve a sugestão de eliminação do acervo. Uma defesa pela guarda dos objetos foi feita pelo professor Luiz Hermínio Marcarini, que lecionou, entre os anos de 1967 a 1999, a disciplina de Física, como em outras situações já detectadas em trabalhos sobre patrimônio escolar. 
muito embora seja possível averiguar a passagem de camadas de verniz, de forma inadequada, em parte dos modelos voltados ao ensino de Zoologia e Fisiologia Humana.

Ainda que não seja o foco imediato da primeira fase do projeto de inventariação, é importante destacar a existência da coleção de História Natural. É desconhecida a quantidade de peças voltadas ao ensino da História Natural e de suas subcategorias (Mineralogia, Botânica, Zoologia), mas existem centenas delas. A coleção contém modelos anatômicos, animais taxidermizados (109 espécies), modelos diversos, coleções de mineralogia, exemplares arqueológicos etc. Madi Filho (2013), na dissertação de mestrado intitulada "Animais taxidermizados como materiais didáticos em fins do século XIX e início do século XX" aponta que a coleção é composta majoritariamente por espécies de biomas brasileiros. ${ }^{7}$

Já o exame técnico panorâmico das peças para o ensino de Física e Química nos mostra que, ao longo das décadas de 1960 e 1970, parte dos objetos sofreram interferências e "consertos" incorretos dentro dos padrões da atual política de salvaguarda de instrumentos tecnocientíficos. Foram utilizando pregos, parafusos e colas, além da aplicação de vernizes que tinham por intenção dar aparência de "arrumado" e que, de forma alguma, tinham a intenção de restauro.

\section{SOBRE OS INVENTÁRIOS E A ORGANIZAÇÃO DE COLEÇÕES}

Entre os historiadores da educação, percebe-se, há mais de 20 anos, o reconhecimento de pesquisas historiográficas que compreendam os aspectos internos da escola por meio da análise da cultura escolar. Viñao Frago (2008, p. 22) explica esse compartilhamento de ações regulares que são sedimentadas ao longo do tempo em teorias, ideias, normas, pautas, rituais, inercias e práticas que constituem a cultura escolar. Vemos o aumento do interesse pela materialidade produzida nessas instituições, exatamente porque objetos possuem uma escritura das ideias, dos modelos pedagógicos e de uma ideologia científica congelada no tempo. A "cultura material escolar" engloba os itens produzidos e utilizados em uma instituição escolar, em diferentes suportes informacionais, fragmentos do passado que possibilitam a construção de uma narrativa histórica.

7 Existem mais 142 peças, usadas em variadas disciplinas científicas, provenientes da coleção de instrumentos científicos do Colégio Marista de Santos, desativado em 2009, e que agora está sob guarda do Memorial do Arquidiocesano de São Paulo. Também estão fora do inventário os modelos anatômicos adquiridos nos anos 1990 pela direção geral da escola, fabricadas pelas empresas Marcus Sommer (desde 1876) e PHYWE (desde 1903), ambas com sede na Alemanha. 
Escolano Benito (2010, p. 14) a vê como "una espécie de registro objetivo de la cultura empírica de las instituciones educativas"; fuentes intuibles y manejables en las que ha quedado materialidade la tradición pedagógica (ESCOLANO BENITO, 2010, p. 14). O autor afirma que esses objetos contribuem para o estudo das disciplinas escolares a partir do conteúdo, seja analisando com base nos programas de oficiais, livros didáticos e registros dos professores, ou explorando a peça para acessar aspectos implícitos do ensino.

$\mathrm{O}$ artefato possibilita também a investigação sobre o método, uma vez que oferece indícios sobre os objetivos pedagógicos, as relações de aprendizado e o comportamento perante o conhecimento (MELONI; GRANATO, 2011, p. 47-48). Enquanto fontes possibilitam compreensão das práticas pedagógicas do passado e colaboram para o aprimoramento da educação no presente (MELONI; GRANATO, 2014, p. 9). Trata-se mesmo de pensar que a manutenção dos objetos acompanha o interesse por pesquisas, em vice-versa. No decorrer dos trabalhos em relação ao memorial/Museu escolar do Colégio Arquidiocesano, surgiram pesquisas de pós-graduação dos participantes do projeto, o que disparou a paulatina descrição das coleções. Essa posição vai ao encontro de se evitar um fetichismo pelo objeto, que, no caso, reside na prática de se colecionar utensílios, artefatos, cuidar deles, sem que haja crítica historiográfica, sem que eles sejam questionados em investigações.

A necessidade de ampliar o espectro de fontes, afirmada pelos historiadores da educação, aponta uma mudança metodológica e teórica dos processos de pesquisa, todavia esbarra nos limites impostos à investigação pelo descaso com as fontes históricas, seja por conta dos descartes aleatórios ou pela ausência de políticas de gestão de patrimônio. A ausência de instrumentos de acesso à informação, como listagens, guias e inventários, também impõe limitações ao pesquisador, muitas vezes obrigado a estabelecer uma ordem, mesmo que precária, para a documentação, abandonada ao fim da pesquisa, mas que resulta em alterações na organização e lacunas (MENEZES, 2011, p. 99).

Pesquisadores alertam sobre as dificuldades na elaboração dos inventários, pois esses exigem um trabalho interdisciplinar, reunindo conhecimentos de museologia, história e educação, entre outras disciplinas do conhecimento. A rotatividade nas equipes envolvidas e a ausência de verbas para as ações têm causado prejuízo "justamente pelo desconhecimento das várias frentes abertas nesse tipo de projeto, nem sempre eles são tratados com o devido merecimento por órgãos de fomento similares” (MENEZES, 2011, p. 113). 
Martins (2006, p. 390), durante o desenvolvimento de projetos de inventariação com escolas na cidade de Campinas, aponta a preocupação pelo envolvimento da comunidade escolar ao Projeto, assim como a sensibilização dos pesquisadores externos que trabalham com as instituições. Para a pesquisadora, deve-se lembrar que a escola não é "apenas o local de guarda de um arquivo, mas a "expressão de uma série de outras memórias, de sucessos e fracassos, da urbanidade do progresso ou da decadência urbana". A escola é um espaço de clivagens de diferentes memórias. Relembra a necessidade de guarda do acervo nas unidades escolares e a importância de um banco de dados (MARTINS, 2006, p. 389-390). ${ }^{8}$

Segundo o Dicionário de Biblioteconomia e Arquivologia o inventário é o documento que descreve e relaciona os bens patrimoniais de um arquivo. É um instrumento de pesquisa, que oferece a descrição, superficial ou minuciosa, de uma coleção ou itens que compõe o acervo. A elaboração de um inventário constitui uma série de ações e organização dos documentos, registro e investigação de uma determinada coleção ou conjunto documental. Contudo, a constituição desses instrumentos de pesquisa é antecedida por uma etapa de trabalho para a conservação do suporte, visto que essas coleções são comumente localizadas nas instituições à beira da destruição, devido às décadas de descaso e intervenções malsucedidas. Ainda há quem as tratem como aglomerados de objetos didáticos obsoletos, ligados às pedagogias antigas.

No caso dos museus, o inventário é uma fonte de produção de conhecimento que permite uma visão integrada sobre os objetos da(s) coleção(s). O conceito de inventário se modificou ao longo do tempo no contexto museológico e houve constante processo de alargamento de sua definição, de modo que hoje torna a própria existência de um museu associada à sua capacidade de bem fazê-lo. Os registos de inventário são formas de localização e reconhecimento do artefato, ferramentas de gestão, de segurança, de investigação, pesquisa e divulgação.

Instituições responsáveis pela salvaguarda e administração de objetos culturais são, ao mesmo tempo, entidades que criam a informação (documental) relacionada às coleções. Por isso, o inventário não está dissociado dos trabalhos ligados aos Sistemas de Informação. Isso significa que o inventário deve ser compreendido, também, como um conjunto ordenado de procedimentos estandalizados que permite a gestão dos objetos e seus fundos documentais e a

\footnotetext{
${ }^{8}$ Diz respeito ao Projeto Memórias da Educação Escolar: Cultura Material e Arquivos Escolares, desenvolvido a partir de 2004, em parceria com o Centro de Memória da Educação da Faculdade de Educação da Unicamp, no qual foram organizados os arquivos escolares do Colégio Progresso Campineiro (1900) e da Escola Estadual Orosimbo Maia, antigo $4^{\circ}$ Grupo Escolar (1925).
} 
exploração metódica da informação mediante as tecnologias adequadas (SIDRA, 2005, p. $13)$.

O sentido de inventariar deve estar integrado num conjunto de linhas de orientação e regras museológicas que reflitam a missão e os objetivos institucionais e que definam estratégias para a gestão das suas coleções. O inventário deve ser ainda um instrumento de gestão integrada. O cumprimento da recuperação da informação de qualquer inventário só é possível se utilizarmos instrumentos, métodos, práticas, linguagens, normalizados. A ausência deste procedimento compromete a qualidade e viabilidade da recuperação da informação, bem como a consistência dos registos que são dependentes da homogeneização de classificações, uniformização de termos, de controle dos procedimentos, ações que visam à organização das designações dos objetos e à definição de categorias de localização e identificação. Essa normalização do inventário é um tema complexo que movimenta debates nacionais e internacionais e, por si só, merece um texto. No entanto, o termo inventário significa esse registo, formado por um conjunto normalizado de ações, conceitos, nomenclaturas e procedimentos.

No caso do museu escolar em análise, a primeira ação foi a elaboração de uma lista dos instrumentos referentes ao ensino de Física, seguindo a necessidade da identificação em 2008. Depois, houve o processo de higienização feita a partir de normas técnicas indicadas à salvaguarda de objetos científicos de composições variadas (madeira, metais, fibras vegetais, papier maché etc.). Para a apresentação desta primeira listagem básica, foi feita a consulta em catálogos de vendas de empresas especializadas que comercializavam as peças, e edições antigas de livros didáticos de Física da Editora F.T.D., elaborados por Irmãos Maristas, também presentes no acervo da escola. Por uma listagem inicial, foram identificadas 685 peças pertencentes aos diferentes ramos de estudos da Física. ${ }^{9}$ Nas coleções, antigamente voltadas ao ensino de História Natural, foi realizada a avaliação dos modelos anatômicos e feito o encaminhamento para o restauro de 15 peças. Há estudo e análise de 109 peças de animais taxidermizados usados para as aulas de Zoologia. Importante ressaltar que as intervenções emergenciais para a preservação, mesmo que com limitações técnica e orçamentária, foram realizadas de forma criteriosa e satisfatória. ${ }^{10}$

\footnotetext{
${ }^{9}$ Os trabalhos de identificação das peças e a descrição básica sobre a utilização do aparelho foram realizados também pelo professor Marcarini, em conjunto com a técnica documentalista a profa. Raquel Quirino Piñas. A listagem não compreende, ainda, toda a coleção do Museu, já que não foram incluídas as peças para o ensino de Química e História Natural. A coleção de mineralogia é formada por mais de mil exemplares de rochas.

${ }^{10}$ Atualmente, há a necessidade de intervenção imediata em outra parte da coleção. Trata-se de peças voltadas à coleção de História Natural procedentes do Colégio Marista de Santos. No final do ano de 2009, com a venda do centenário Colégio Marista de Santos para o Município, foi realizada a transferência de seus acervos. São objetos
} 


\section{TRABALHOS RECENTES NO COLÉGIO MARISTA ARQUIDIOCESANO E O BANCO DE DADOS PERGAMUM}

No caso do Colégio Marista Arquidiocesano de São Paulo, iniciou-se o processo pela higienização, guarda adequada do objeto e avaliação do estado de conservação e se há necessidade de intervenções emergenciais para a preservação do suporte.

Para tanto, a equipe tem acompanhado os estudos feitos por outras equipes científicas que trabalharam tanto com materiais científicos, quanto nos inventários de materiais didáticos científicos. São trabalhos desenvolvidos no exterior, principalmente na França (Institut National de Recherche Pédagogique (INRP) e do Service d'histoire de l'éducation - SHE e a Association de Sauvegarde et d'Étude des Instruments Scientifiques et Techniques de l'Enseignement - ASEISTE); Portugal (Projeto: Educação e Património Cultural: Escolas, Objetos e Práticas); Espanha (Sociedade Espanhola para o Estudo do Patrimônio HistóricoEducativo - SEPHE, o Centro Internacional de Cultura Escolar - CEINCE, e o Centro de Estudios sobre la Memoria Educativa- CEME). ${ }^{11}$

No Brasil, trabalhos em torno do patrimônio científico escolar ainda são escassos. Destacam-se: 1) Museu de Astronomia e Ciências Afins (MAST) com a pesquisa sobre o Laboratório de Física do Colégio Pedro II (RJ), no qual desde 2007, vem sendo desenvolvidos trabalhos de pesquisa, preservação e tratamento técnico de aproximadamente 738 objetos datados do início do século XX; 2) "Saberes em Ciências Naturais: o ensino de Física e Química no Colégio Culto à Ciência de Campinas - 1873/1910”, trabalho de Doutorado em Educação defendido na Unicamp pelo prof. Reginaldo Meloni, apontando a inventariação e os

que constituíram o Museu Escolar e se encontravam abandonados há décadas. Foram realizados os primeiros trabalhos de higienização, transporte e listagem de identificação básica das peças. Essa coleção é constituída por 142 itens, essencialmente instrumentos para o ensino de Física. Destas, duas peças apresentam um avançado estado de deterioração, principalmente causado pela ação de cupins na base de madeira, um galináceo e um anfíbio, ambos feitos com base de fibra de cânhamo envoltos por papier mâché. Há marcas da ação dos fatores climáticos decorrentes do fenômeno da maresia (ferrugem, corrosão etc.). Encontram-se selados e guardados nos mezaninos dos laboratórios de Física e Biologia, visto que a instituição não dispõe de espaço adequado para a organização de tamanha coleção e, até então, não cedeu recursos financeiros, nem para o tratamento e restauro dessas peças, nem para a ampliação dos espaços de guarda. O diagnóstico desta coleção está sendo feita pela equipe do projeto com vistas a elencar as peças que necessitam de intervenções mais urgentes e possíveis restauros.

11 Os projetos são respectivamente coordenados por: Bruno Belhoste e Henry Chamoux que inventariaram os objetos de ciências das escolas secundárias francesas no Institut National de Recherche Pédagogique (INRP) e do Service d'histoire de l'éducation (SHE). A ASEISTE se propõe a colaborar com as escolas na constituição de museus escolares científicos. Possui um inventário virtual com 4.000 objetos, com origem em mais de 40 escolas secundárias. Na Espanha, o SEPHE é uma rede que trata do patrimônio histórico escolar; o CEINCE é dirigido por Escolano Benito e o CEME, da Universidade de Murcia é dirigido por Pedro Luis Moreno Martinez nos dias atuais. Em Portugal, vemos essa preocupação nas pesquisas da profa. Maria João Mogarro que se dedicou às 
usos históricos da coleção científica do Colégio Culto à Ciência de Campinas; 3) "Os instrumentos antigos do Laboratório de Física da escola estadual Bento de Abreu de Araraquara", apresentado pela profa. Maria Cristina Zancul, demonstrando a inventariação dos objetos científicos da Escola Bento de Abreu, em Araraquara, antes, Araraquara College e Ginásio Municipal Mackenzie; 4) "Museu Escolar do Colégio Marista Arquidiocesano de São Paulo: constituição, histórico e primeiros movimentos de salvaguarda da coleção" (BRAGHINI; PEDRO; PINÃS, 2014), sobre as primeiras intervenções no trato das coleções.

Já a identificação das peças será atribuída à nomenclatura, o ramo científico no qual a peça está classificada, considerando denominações de inventários anteriores e outros nomes que possam ser atribuídos ao item. Como esclarece Meloni e Granato (2011, p.55-56), não existe uma uniformidade histórica dos nomes dos aparelhos, variando de acordo com o uso, fabricante, ou cientista descobridor do fenômeno. Há, ainda, os registros feitos em inventários escolares cujas denominações variam bastante, denotando, inclusive, que os responsáveis pelas listagens não tinham o domínio dos nomes dos objetos.

No entanto, o inventário em foco parte da ideia de uniformização terminológica no campo de identificação inicial, pensando os termos de uma nomenclatura universal de objetos científicos. A nomenclatura padrão visa à facilitação da comunicação entre pesquisadores, de modo a promover a pesquisa pelo intercâmbio; mirando uma valorização conjunta do patrimônio científico e escolar. A uniformização terminológica está amparada pelos trabalhos de uma rede de museus de ciências, sob a coordenação do MAST, que organizou o Thesaurus de Instrumentos Científicos em Língua Portuguesa, fonte de consulta deste inventário. ${ }^{12}$

Os campos descritivos da ficha de registro foram sugeridos por Granato et al. (2013, p. 5). Os autores aconselham como um modelo de ficha de registro e descrição de objetos científicos, composto pelos seguintes campos: foto representativa do objeto, localização, estado de conservação, documentos associados (notas fiscais, etc.), compilador/data (dados do responsável pela descrição), descrição e função do objeto, denominação, nome vulgar,

pesquisas do patrimônio educacional por uma perspectiva histórica, por meio dos estudos da escola por meio da materialidade, fazendo a articulação entre os objetos e as atividades pedagógicas.

12 Instituições componentes - Portugal: MCUL: Museu de Ciência da Universidade de Lisboa (Instituição Coordenadora), MCUP: Museu de Ciência da Universidade do Porto, MCUC: Museu da Ciência da Universidade de Coimbra, MFEUP: Serviço de Documentação e Informação - Museu da Faculdade de Engenharia da Universidade do Porto, MISEP: Museu do Instituto Superior de Engenharia do Porto, ISEL: Museu de Física do Instituto Superior de Engenharia de Lisboa, MNCT: Museu Nacional da Ciência e da Técnica/ Brasil: MAST: Museu de Astronomia e Ciências Afins, Rio de Janeiro (Instituição Coordenadora), UFOP: Museu de Ciência e Técnica da Universidade Federal de Ouro Preto, MDCT-UFJF: Museu Dinâmico de Ciência e Tecnologia da Universidade Federal de Juiz de Fora, MEP-UFRJ: Museu da Escola Politécnica da Universidade Federal do Rio de Janeiro, IBICT: Instituto Brasileiro de Informação em Ciência e Tecnologia, Ministério de Ciência e Tecnologia. Disponível em: <http://chcul.fc.ul.pt/thesaurus/>. Acesso em: 01 mar. 2014. 
número, materiais, dimensões, fabricante, marcas/inscrições, legendas e ano de fabricação. A descrição individual do objeto apresenta as dimensões físicas e características materiais, indica sua procedência/fabricação e possível datação, inclui as inscrições e marcações existentes e o uso para o qual o artefato se destinava.

Tal ficha de identificação dos objetos científicos foi construída dentro da base de dados intitulada Pergamum Museu. A Rede Marista utiliza o sistema Pergamum desde 2003 para a gestão da coleção bibliográfica institucional. ${ }^{13}$ A Pontifícia Universidade Católica do Paraná (PUC-PR) é detentora dos direitos autorais e responsável pela comercialização deste banco de dados. Em 2011 a equipe de programação do software iniciou o desenvolvimento de um módulo específico para coleções museológicas.

Tal como ocorre com a catalogação de materiais bibliográficos, o Pergamum Museu utiliza a Machine Readable Cataloging (MARC) ${ }^{14}$ na definição dos campos da planilha e para a inserção dos dados. A partir do plano de criação de uma ficha de identificação e do apontamento de critérios de inventariação, a máquina pode ler e interpretar os dados no registo de catalogação. A moldura básica do formato contém informações de controle, necessárias para transmissões de informações e define o layout dos campos de dados. A estrutura é genérica e serve a qualquer tipo de dados bibliográficos, além, de poder ser adaptada às necessidades de processamentos e à configuração de equipamentos museológicos.

A inserção dos dados no sistema é facilitada devido à possibilidade de se realizar o cadastro prévio de algumas informações. Após a inclusão de um dado, nos espaços destinados, por exemplo, às palavras-chave ou fabricantes de peças, ele é gravado pelo sistema informatizado. Posteriormente, as mesmas palavras, quando repetidas nestes mesmos espaços, podem ser visualizadas automaticamente. Isso evita que o pesquisador tenha que fazer a reinserção manual, caso a caso, de dados refletidos. As figuras 1 e 2 representam essa possibilidade de procedimento, a título de ilustração.

\footnotetext{
${ }^{13}$ Para a escolha desse sistema, foi avaliada sua capacidade de armazenamento de dados, suas funcionalidades que abarcam praticamente todas as rotinas administrativas necessárias para o adequado funcionamento de uma biblioteca - e a sua receptividade no mercado de softwares para o gerenciamento de Bibliotecas. Tem sido apontado como um dos melhores do gênero em território nacional e utilizado por mais 230 instituições (bibliotecas, centros de memória, tribunais de justiça, ONGs, conselhos regionais, empresas, etc.).

${ }^{14}$ Maranhão e Mendonça (2014) apresentam esse formato como "um conjunto de códigos e designações de conteúdos definido para codificar registros que serão interpretados por máquina”. Possivelmente a característica mais marcante dessa codificação é permitir a troca de dados entre instituições, ou seja, ela viabiliza o diálogo mais seguro entre bases de dados quando há a necessidade de exportação de informações”.
} 
Figura 1: Introdução do nome do fabricante da peça.

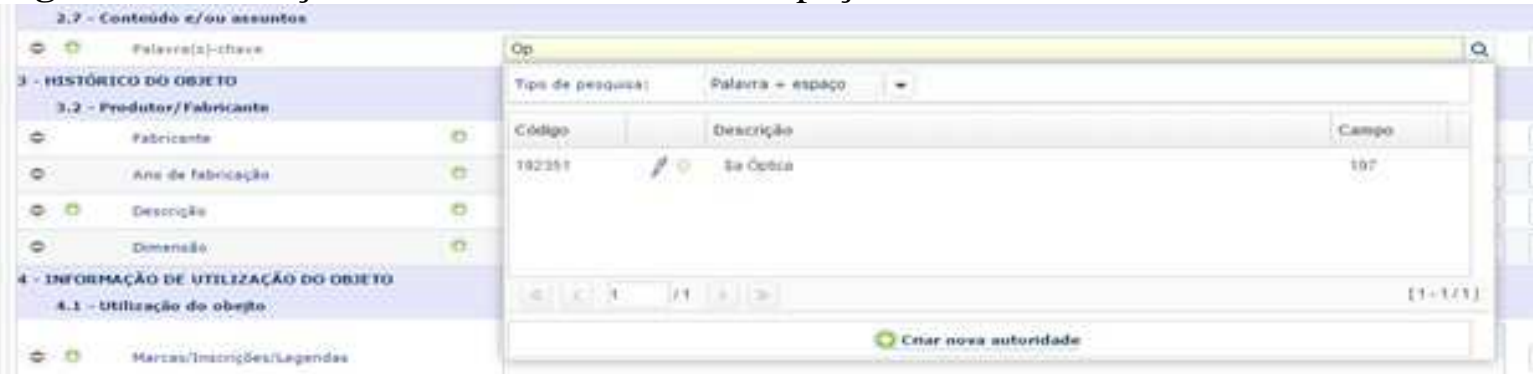

Fonte: Banco de dados: Pergamum Museu. Memorial do Colégio Marista Arquidiocesano de São Paulo.

Figura 2: Introdução de palavras-chave.

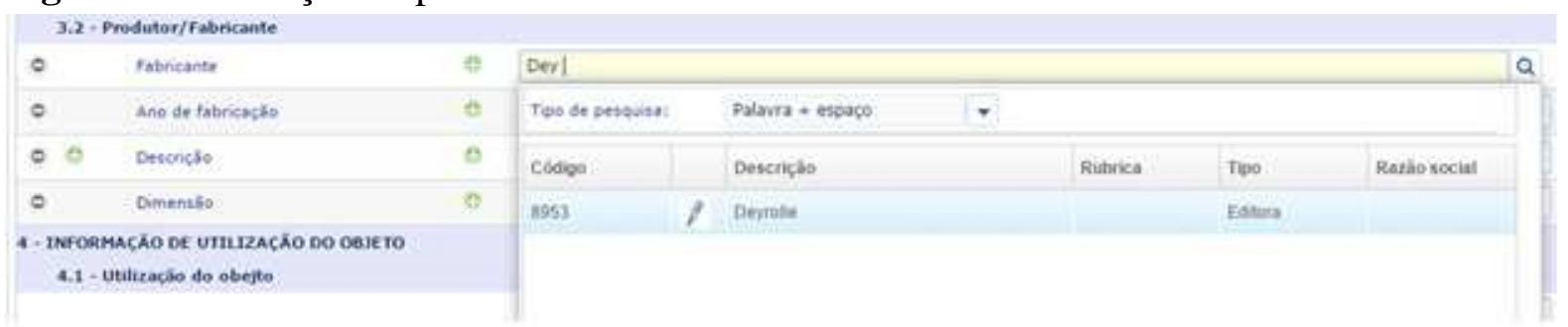

Fonte: Banco de dados: Pergamum Museu. Memorial do Colégio Marista Arquidiocesano de São Paulo.

Também optou-se por deixar registrado na ficha o estado de conservação das peças de forma que seja possível selecionar a qualificação do item, sem que haja necessidade de digitar os respectivos termos: "bom”, "regular", "ruim”.

Figura 3: Introdução do estado de conservação da peça.

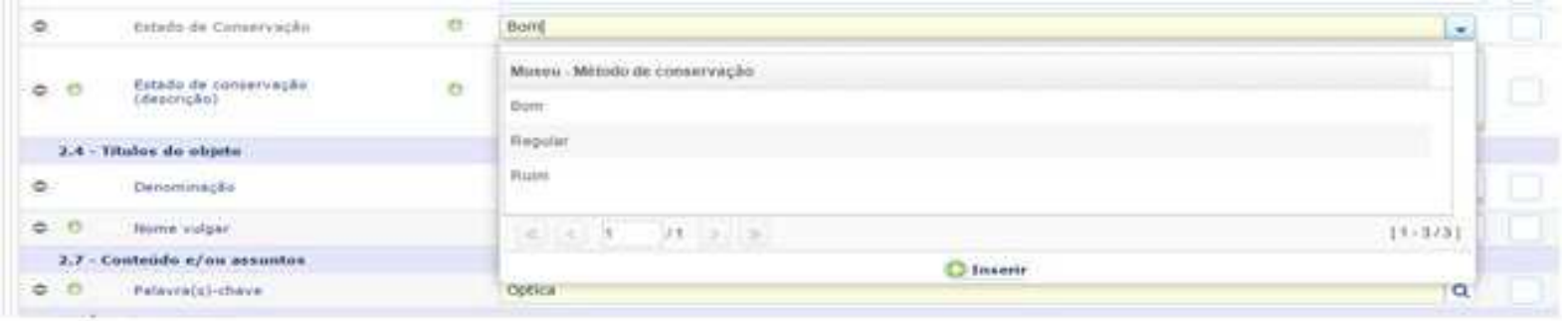

Fonte: Banco de dados: Pergamum Museu. Memorial do Colégio Marista Arquidiocesano de São Paulo.

As informações obtidas são sistematizadas nas fichas e o registro visual é feito por meio de fotografias da peça em diferentes ângulos. Posteriormente, é realizada a inclusão dos dados e imagens em plataforma digital para futuras consultas. Os estudos a partir desses objetos busca compreender a origem, sua função, as prescrições legais e concepções em torno do ensino de ciências que nortearam seus usos nas instituições educacionais em diferentes contextos.

Além das questões estruturais, existe uma preocupação em aperfeiçoar e criar novas ferramentas, a partir das demandas apontadas pelos usuários, pesquisadores. Dentre as 
demandas particulares, há a necessidade de apresentar as referências visuais em registros descritivos. Esses procedimentos auxiliam no processo de identificação de coleções que exigem um maior grau de especificidade. É possível enriquecer o registro com fotografias, imagens e links, que são recursos importantes quando levamos em consideração aspectos relacionados às questões de preservação e a difusão do conhecimento. ${ }^{15}$

Em linhas gerais, o padrão MARC possibilita adicionar informações, definir campos para uso local, atualizar informações existentes, atribuir pontos de acesso recuperáveis e possibilita a catalogação cooperativa por meio da ideia de interoperabilidade. O conceito de interoperabilidade está relacionado à troca e compartilhamento de informações a partir de pesquisas, de mesmo caráter, possibilitando que bases de dados de diferentes instituições sejam intercambiados, gerando, assim, o compartilhamento da informação (DZIEKANIAK et al., 2008, p. 3). ${ }^{16}$

Houve a opção por um sistema informatizado para a guarda de informações. Porém, ele não é único e nem deve ser entendido como ferramenta definitiva de acolhimento de dados. É necessário o registro manual no livro tombo, levando em conta a ideia de resguardo de informações. Além disso, os pesquisadores devem analisar com rigor os dados registrados no território da máquina, fazendo a revisão dos dados de tempos em tempos até o encerramento dos trabalhos.

O registro informatizado vai ao encontro das vantagens apontadas por Rowley (1994 apud GOMES, 2006, p.1), resumidas em duas propostas: os dados serão inseridos uma única vez e podem ser acessados e modificados; os sistemas propiciam a introdução de serviços que não existiam antes, e assim, ajudam no processamento de um volume maior de trabalho de pesquisa. A informatização dos registros abre novas possibilidades de uso para os dados "brutos" e apresenta ferramentas interessantes para a idealização de procedimentos de pesquisa. É uma ferramenta útil para a identificação e mapeamento das particularidades de um determinado acervo

\footnotetext{
${ }^{15}$ Dentro deste contexto são organizados periodicamente encontros nacionais e regionais como uma estratégia para facilitar a troca de informações, mapear novas necessidades e conhecer práticas de excelência relacionadas ao uso do Pergamum.

${ }^{16}$ O padrão MARC tem a sua história marcada no final dos anos 1950 pela iniciativa da Library of Congress (LC) que planejou um primeiro movimento para automatizar suas operações. Entre os anos de 1965-1966, após algumas conferências entre a LC e outros órgãos, como a Counsil on Library Resources (CLR) foi apresentado o padrão aberto de catalogação conhecido como MARC. Ele foi criado pela LC para padronizar a estrutura, o conteúdo e a codificação dos arquivos bibliográficos armazenados em fichas catalográficas e convertê-las para o meio legível por máquina. A ideia era a de que o computador pudesse ler e interpretar a informação num registro bibliográfico, primeiro visando a organização do acervo próprio, depois, de modo a possibilitar o intercâmbio de registros entre bibliotecas.
} 
Outro benefício é a geração de outros instrumentos de pesquisa que podem ser extraídos do sistema, tais como catálogo, listagens dos mais diversos tipos, emissão de etiquetas (não adesivas) para identificação dos objetos por meio de código de barras etc. $\mathrm{O}$ sistema também permite controlar a circulação dos itens das coleções, para ser colocado à disposição de pesquisadores ou para as atividades nos laboratórios e, eventualmente, nas salas de aula, já que as peças, sendo patrimônio escolar, ainda são utilizadas como materiais pedagógicos na escola.

\section{CONSIDERAÇÕES FINAIS}

Entre os anos iniciais do século XX até aproximadamente os anos 1940, o colégio foi transformando os seus espaços escolares voltados às ciências e, progressivamente, outros objetos foram sendo adicionados às coleções. Percebeu-se que os objetos foram adquiridos por responsáveis pelo colégio por vários motivos: acompanhar a diretriz da própria instituição que seguia dentro de procedimentos internos as determinações do Guide des Écoles manual de trabalho dos Irmãos Maristas que pregavam o ensino prático por meio da apresentação de objetos, principalmente para o ensino de Lições de Coisas (ASSIS, 2013, p. 148); pelo desejo de se tornar uma instituição equiparada ao Colégio Pedro II o que exigia compra acentuada de matérias de ensino para todas as disciplinas e que eram apresentadas como requisitos dentro do próprio processo (PEDRO, 2014, p. 30 e 78); pela organização dos espaços destinados às ciências, que foram acompanhando as prescrições legais orientadas para cada disciplina e que fomentavam a organização dos espaços destinados às aulas (gabinetes, laboratórios, museu) a terem os seus respectivos objetos (BOCCHI, 2013, p. 43); pela apresentação prestigiosa que tais espaços ocupados davam ao colégio diante da concorrência com outras instituições de ensino, fossem elas privadas ou públicas (BRAGHINI, 2015, p. 9).

$\mathrm{Na}$ última década, aconteceu o surgimento de iniciativas dedicadas ao estudo e à organização de coleções de objetos de ensino de ciências que intencionam a elaboração de guias de acervos, inventários e catálogos, com objetivo de preservar o patrimônio e promover sua divulgação. A inventariação de um acervo é uma ação que se constitui como essencial uma vez que permite pela coleta e sistematização das informações, a elaboração de um mapeamento dos itens que compõe o acervo e situá-los na trajetória da instituição escolar. O inventário oferece ao pesquisador o documento, tratado, organizado e estudado, além de propiciar o exercício de converter a cultura material escolar em fonte para investigação. 
Os trabalhos com as coleções do Colégio Marista Arquidiocesano já passaram pela etapa de organização, higienização, diagnóstico técnico das peças e a criação de uma prélistagem de uma parcela dos objetos científicos. Os trabalhos acerca do inventário passam agora pelos movimentos de sensibilização da comunidade escolar em torno de tal investimento de pesquisa. No momento, busca-se uma ação compartilhada com alunos e estagiários técnicos no sentido de alimentação do banco de dados, após os debates sobre a organização da ficha e levantamento histórico da coleção científica da instituição. ${ }^{17}$

Ainda estão sendo realizados os primeiros testes com o uso da base de dados do sistema Pergamum, no entanto, a utilização feita por museus no estado do Paraná e a analise preliminar dos dados necessários para uma identificação essencial dos objetos da coleção do Arquidiocesano, a partir da ficha sugerida por Granato et al. (2013), já permitem ter um panorama positivo da inclusão dos dados diretamente em meio digital, com a vantagem de também possibilitar o aumento dos campos para descrição sem que haja perda dos dados inseridos ou maiores dificuldades nesse sentido, uma vez que são amplas as possibilidades viabilizadas pelo software e pelo MARC.

Após uma análise preliminar, não foi constatada incompatibilidades significativas entre os campos descritivos da ficha de registro sugerida por Granato et al. (2013, p.5) para objetos científicos, com a codificação do Pergamun Museu que possibilita a descrição de artefatos.

Concluímos, lembrando que a ideia de "interoperabilidade" não depende apenas de requisitos técnicos. A sua operação necessita da discussão antecipada dos critérios elencados para a organização da base de dados e de análise das pesquisas já produzidas, no caso sobre os artefatos científicos, de modo que haja a possibilidade de criação de vínculos de compartilhamento dentro das regras de normalização de documentação no âmbito museal, seja nos termos de controle das terminologias ou na constituição da estrutura de dados.

\section{REFERÊNCIAS}

ANZOLIN, Heloisa Helena. Rede Pergamum: história, evolução e Perspectivas. Revista ACB, Florianópolis, v. 14, n. 2, p. 493-512, jul./dez. 2009. Disponível em: <http://revista.acbsc.org.br/racb/article/view/640/pdf_9>. Acesso em: 11 jun. 2015.

17 Trata-se do "Projeto Escolha" projeto escolar que visa à discussão sobre vocações profissionais, direcionado aos alunos do ensino médio. O projeto pedagógico relacionado aos objetivos de inventariação das coleções do museu escolar do colégio intitula-se "O ofício do historiador". Do "Projeto Escolha" foram escolhidas quatro jovens pesquisadoras iniciantes, alunas do Ensino Médio, Mariana Mattos, Lívia Bandeira, Victória Alves e Larissa Cote.

Rev. Iberoam. Patrim. Histórico-Educativo, Campinas (SP), v. 2, n. 2, p. 73-91, jan./jun. 2016 
ASSIS, Paula Maria de. A educação dos sentidos nas Escolas Maristas: o Guide des Écoles. 2013. 166 f. Tese (Doutorado em Educação) - PEPG em Educação: História, Política, Sociedade da Pontifícia Universidade Católica de São Paulo.

BOCCHI, Luna Abrano. A configuração de novos locais e práticas pedagógicas na escola: O museu escolar, os laboratórios e gabinetes de ensino do Colégio Marista Arquidiocesano de São Paulo (1908-1940). 2013. 137 f. Dissertação (Mestrado em Educação) - PEPG em Educação: História, Política, Sociedade da Pontifícia Universidade Católica de São Paulo.

BRAGHINI, Katya M. Z. A relação entre os professores de ciências e as empresas fabricantes de produtos didáticos científicos em São Paulo, primeira metade do século xx: compra, correspondência, circulação de conhecimento. Congresso Brasileiro de História da Educação. Matrizes interpretativas e internacionalização. Sociedade Brasileira de História da Educação. Anais... Maringá, 2015.

; PIÑAS, Raquel Quirino; PEDRO, Ricardo Tomasiello. Museu Escolar do Colégio Marista Arquidiocesano de São Paulo: Constituição, histórico e primeiros movimentos de salvaguarda da coleção. Revista Esboços, Florianópolis, v. 21, n. 31, p. 28-49, ago. 2014.

CÓDIGO de catalogação Anglo-Americano. 2.ed. São Paulo: FEBAB; Imprensa Oficial.

DZIEKANIAK, Gisele Vasconcelos et al. Uso do padrão MARC em bibliotecas universitárias da região sul do Brasil. Encontros Bibli. Revista Eletrônica de Biblioteconomia e Ciências da Informação. Universidade federal de Santa Catarina. v. 13, $\mathrm{n}^{\circ} 26,2008$.

ESCOLANO BENITO, Agustín. Patrimonio material de la escuela e historia cultural. Revista Linhas, Florianópolis, v. 11, n. 02, p. 13-28, jul./dez. 2010. Disponível em: <http://www.revistas.udesc.br/index.php/linhas/article/viewFile/2125/1628> Acesso: 13 jul. 2015.

FERREIRA, Marcela de Almeida et al. O conjunto de objetos de ensino do Laboratório de Física do Colégio Pedro II. In: GRANATO, Marcus; LOURENÇO, Marta C. (Orgs.). Coleções Científicas Luso-Brasileiras patrimônio a ser descoberto. Rio de Janeiro: Museu de Astronomia e Ciências Afins, 2010, p. 123-143.

FURRIE, Betty. O MARC bibliográfico: um guia introdutório: catalogação legível por computador. Tradução de Beatriz Valadares Cendón, Sonia Burnier, Maria Helena Santos e Natália Guiné de Mello Carvalho. Brasília, DF: Thesaurus, 2000. (Título original: Understanding MARC Bibliographic)

GIRES, Francis. LAUGINIE, Pierre. A ASEISTE e a preservação do Patrimônio Científico e Técnico do Ensino. XXXI Simpósio Anual da Scientific Instruments Commission. Rio de Janeiro, out. 2012. Disponível em: 〈http://www.aseiste.org/documents/aa_portugais.pdf>. Acesso em:11 jun. 2015.

GOMES, Carolina Glayce. Avaliação da usabilidade do sistema Pergamum de gerenciamento de bibliotecas. In: SEMINÁRIO NACIONAL DE BIBLIOTECAS UNIVERSITÁRIAS, 14, 2006, Salvador. Anais... Salvador, 2006. Disponível em: 
<http://www.pergamum.pucpr.br/redepergamum/trabs/UsabilidadePergamum.pdf $>$. Acesso em 12 jun. 2015.

GRANATO, Marcus et al. Cartilha de orientações gerais para preservação do patrimônio cultural de ciência e tecnologia. Rio de Janeiro: Museu de Astronomia e Ciências Afins, 2013.

GRANATO, Marcus. Instrumentos de precisão: fonte para a história e estratégias para a permanência. Revista da Sociedade Brasileira de História das Ciências, v. 2, nº 2, jul/dez. p. 133-145, 2004.

MADI FILHO, José Maurício Ismael. O uso de animais taxidermizados como materiais de ensino em fins do século XIX e começo do XX. 2013. 143 f. Dissertação (Mestrado em Educação) - PEPG em Educação: História, Política, Sociedade da Pontifícia Universidade Católica de São Paulo.

MARANHÃO, Ana Maria Neves; MENDONÇA, Maria de Lourdes dos Santos. MARC 21 formato bibliográfico. Rio de Janeiro: Divisão de Bibliotecas e Documentação (PUC-RJ), 2014. Disponível em: <http://www.dbd.puc-rio.br/MARC21/index.html>. Acesso em: 12 jun. 2015.

MARTINS, Maria do Carmo. Memórias da educação escolar: prospecções e projeções. Cadernos do CEOM, Centro de Memória do Oeste de Santa Catarina, v. 9, n. 25, ano 19, dez. 2006.

MELONI, Reginaldo Alberto; GRANATO, Marcus. Objetos de Educação em Ciências: um patrimônio a ser preservado. Revista Pedagogia em Foco, Iturama (MG), v. 9, n. 2, jul./dez. 2014.

A experiência de constituição de uma fonte documental a partir dos instrumentos de ensino de química e física do Colégio Culto à Ciência de Campinas/SP. Revista Brasileira de História da Educação, Campinas, v. 11, n. 1 (25), p. 43-65, jan./abr. 2011.

MENEZES, Maria Cristina. Descrever os documentos - construir o inventário - preservar a cultura material escolar. Revista Brasileira de História da Educação, Campinas-SP, v.11, n.1 (25), p.93-116, jan./abr. 2011.

MESSINA-RAMOS, Maria Angélica Ferraz. Manual para entrada de dados bibliográficos em formato MARC 21: ênfase em obras raras e especiais. Belo Horizonte: Ed. UFMG, 2011.

PEDRO, Ricardo Tomasiello. História da equiparação do Colégio Marista Arquidiocesano de São Paulo ao Colégio Pedro II (1900-1940). 2014. 176 f. Dissertação (Mestrado em Educação) - PEPG em Educação: História, Política, Sociedade da Pontifícia Universidade Católica de São Paulo.

ROWLEY, Jennifer. Informática para bibliotecas. Tradução de Antonio Agenor Briquet de Lemos. Brasília: Briquet de Lemos/Livros, 1994 apud GOMES, Carolina Glayce. Avaliação da usabilidade do sistema Pergamum de gerenciamento de bibliotecas. In: SEMINÁRIO NACIONAL DE BIBLIOTECAS UNIVERSITÁRIAS, 14, 2006, Salvador. Anais... 
Salvador,

2006.

Disponível

em:

$<$ http://www.pergamum.pucpr.br/redepergamum/trabs/UsabilidadePergamum.pdf $>$. Acesso em 12 jun. 2015.

SIDRA: Sistema de Información Documental en Red de Asturia. Introducción. Oviedo: AABADOM, 2005.

Disponível

em:

<http://aabadom.files.wordpress.com/2009/09/100_0.pdf〉. Acesso em: 11 jun. 2015.

VIÑAO FRAGO, Antonio. La escuela y la escolaridad como objetos históricos: Facetas y problemas de la história de la educación. História da Educação, Pelotas, v. 12, p. 9-54, 2008.

ZANCUL, Maria Cristina de Senzi. A coleção de instrumentos antigos do laboratório de Física da Escola Estadual Bento de Abreu de Araraquara. Ensaio Pesquisa em Educação em Ciências, v. 11, n. 1, p. 1-17, jun. 2009. 